des différents éléments, deuxième partie: climatologie des diverses régions de la Suisse, troisième partie: climatologie des types de temps.

Cet ouvrage devrait être terminé en 1971 ; les méthodes les plus modernes (p. ex. cartes perforées) y seront utilisées. Le réseau des stations devient toujours plus malaisé à maintenir; il faudra songer à automatiser, ce qui n'est cependant pas facile pour quelques-uns des éléments. Pour la synoptique, des méthodes ont été développées, qui permettent de calculer les cartes de courants en altitude 24 à 96 heures à l'a vance. La prévision à moyenne et à longue échéance est cependant encore peu avancée. De nombreuses recherches seront encore nécessaires pour en améliorer les résultats.

\title{
DER GEIRANGERFJORD
}

\author{
OSKAR BÄR
}

Mit Farbbild

Kaum anderswo durchdringen sich Land und Meer so innig wie im südwestlichen Norwegen. Zwischen dem 59. und dem 63. Breitengrad stößt die See in rund einem Dutzend markantester Fjorde tief ins Land hinein vor. Der in unserer Farbtafel abgebildete Geirangerfjord, einer der nördlichsten in der berühmten Gruppe, zählt zu den schönsten und bekanntesten.

Die Fahrt dorthin führt vom Bredsund, etwas südlich des Hafenstädtchens Aalesund $\left(62^{\circ} 28^{\prime} \mathrm{n}\right.$. Br. $)$, vorerst in den Storfjord. Dieser anfänglich 4 bis $6 \mathrm{~km}$ breite Fjord weist ziemlich genau nach Osten, wo er nach rund $50 \mathrm{~km}$ scharf südwärts abbiegt und sich nach weitern $25 \mathrm{~km}$ verzweigt. Die beiden Arme, der Nordalsfjord (ostwärts) und der Sunelvsfjord (25 km südwärts bis Hellesylt) sind wunderbar schmale, von 1000 $1500 \mathrm{~m}$ hohen Felswänden eingefaßte Wasseradern. Im rechten Winkel zum Sunelvsfjord erstreckt sich der Geirangerfjord in sanfter Wellenlinie $15 \mathrm{~km}$ nach Osten und endet, sich zwischen steilen Wänden auf $800-1000$ m verengend, in Geiranger. In unserem Bild umfährt das Motorschiff «Oslofjord» die letzte Biegung, um nach etwa $5 \mathrm{~km}$ dieses Ziel zu erreichen.

Die Fjordlandschaft vermag uns stets aufs neue zu begeistern, und immer wieder taucht die Frage nach ihrer Entstehung auf. Fließendes Wasser und Gletschereis haben sich in die Erosionsarbeit geteilt. Die schon voreiszeitlich im Granit und Gneis des abgetragenen Kaledonischen Gebirges angelegten Flußtäler wurden zur Eiszeit umgeformt. In schmalen Rinnen konzentriertes und deshalb sehr rasch abfließendes Inlandeis leistete die Hauptarbeit. Je enger diese Abflußdüsen beschaffen waren, um so wirkungsvoller wurden sie vertieft, meistens bis rund $500 \mathrm{~m}$ unter den Meeresspiegel. Der $180 \mathrm{~km}$ lange Sognefjord hat in der Mitte sogar eine Tiefe von $1240 \mathrm{~m}$. Am Fjordausgang reicht aber eine Felsschwelle bis $100 \mathrm{~m}$ unter die Wasseroberfläche - ein Hinweis auf die entscheidende Wirkung der Gletschererosion. Wenn man bei uns die Alpenrandseen, vor allem den Urner- und den Walensee, mit den norwegischen Fjorden vergleicht, sollte ein wesentlicher Unterschied nicht außer acht gelassen werden: während sich in den Alpen über den glazialen Trogtälern überall zackige, frostverwitterte Gräte aufschwingen, die nie unter dem Eis der alpinen Gletscher begraben waren, erwartet uns über den Fjordwänden nichts ähnliches.

Die im Hintergrund des Bildes noch erkennbare, leicht gewellte und teilweise mit Schnee bedeckte Hochfläche nennt man im Norwegischen «Fjeld» oder «Fjell». Kanten und Gräte wurden dort während der Vergletscherung unter der mächtigen skandinavi- 


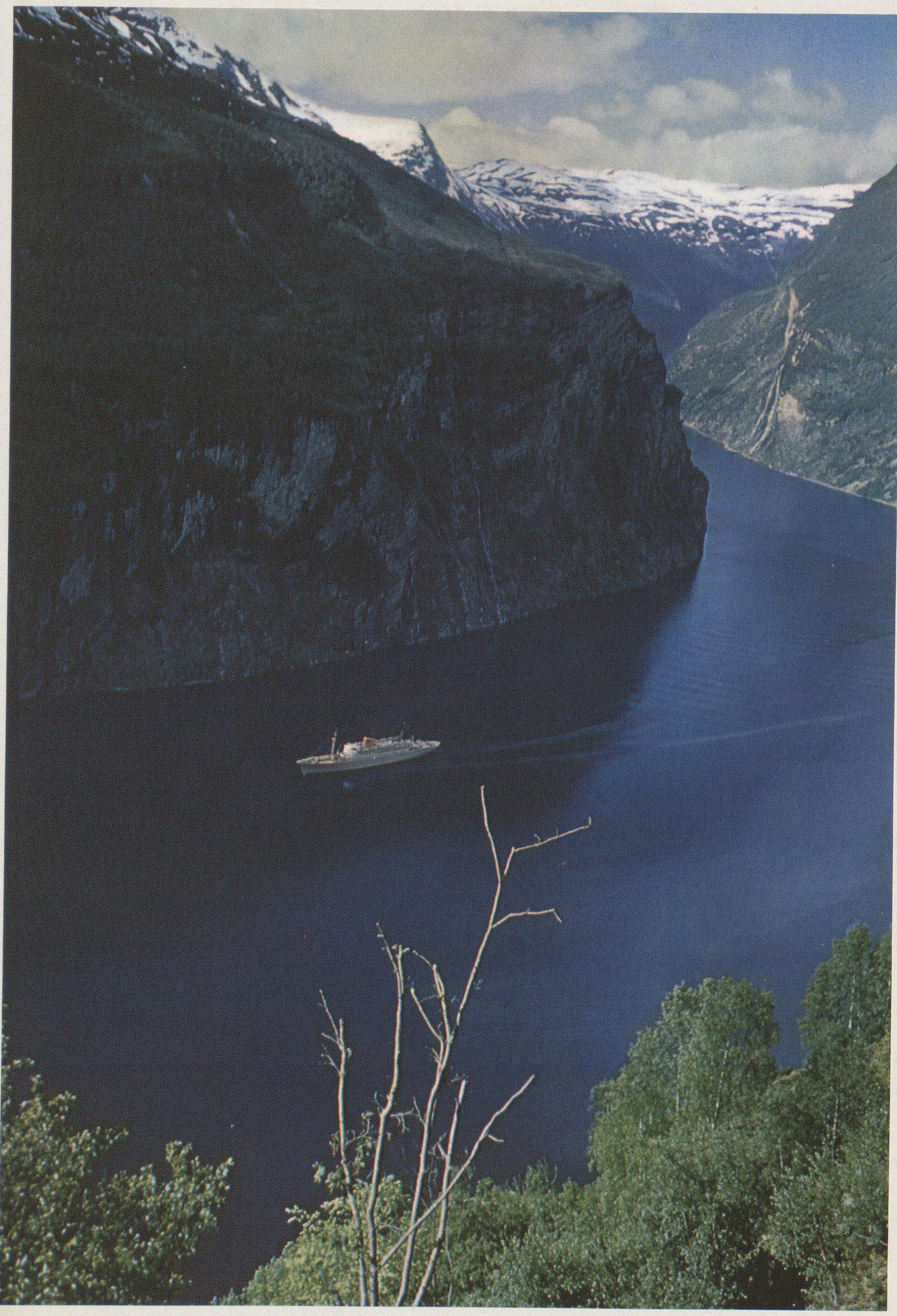


schen Eiskappe gerundet. Da und dort entstanden weite U-Täler, die in scharfen Gefällsbrüchen unvermittelt zum steilwandigen Fjord abstürzen. Tiefe Mündungsschluchten wurden seit der Eiszeit nur von wenigen Bächen geschaffen. Meist schießt das Wasser von der Hochfläche in Kaskaden zum Fjord hinab oder zerflattert als Fos (Wasserfall) an der steilen Felswand. Ein sehr schönes Beispiel dafür sind die «Sieben Schwestern» (Syv Söstre), sieben nebeneinander über die nördliche Wand stürzende Bäche. Im Bild hat das Schiff diese Stelle vor der Biegung soeben backbord passiert.

Fjordlandschaften sind wohl sehr malerisch; aber dies darf uns nicht über die kargen Lebensbedingungen hinwegtäuschen. Die Hochfläche liegt in dieser Breitenlage bereits über der Dauersiedlungsgrenze und kann nur noch «alpwirtschaftlich» genutzt werden (Säterwirtschaft) ; in den Fjorden selber sind jedoch die Siedlungs- und Wirtschaftsflächen beschränkt. Nur Verflachungen in weniger steilen Hängen, eiszeitlich abgeschliffene Sporne an der Einmündung kleiner Fjordarme oder nacheiszeitliche Deltas und Terrassen stehen landwirtschaftlicher Nutzung offen. Sorgsam mit Roggen, Hafer, Gerste oder Kartoffeln bepflanzte Äckerchen und kleine Heuwiesen sind aus topographischen und klimatischen Gründen (Besonnung) oft weit zerstreut - mit ihnen auch die vielen Einzelhöfe (Gaard). Die Siedlungskerne (Herred) bestehen in vielen Fällen nur aus Kirche, zwei bis drei Gehöften und manchmal Schule oder Kaufladen. Daß im Bild keine solchen Siedlungen zu erkennen sind, hängt mit der außerordentlichen Steilheit in diesem Abschnitt zusammen. Bereits wenige Kilometer fjordauswärts sind sie wieder vorhanden, desgleichen am Fjordende. Verbindungswege fehlen vielfach zwischen den abgelegenen Höfen. Nur über das Wasser des Fjords wird der Kontakt zu Nachbar und Außenwelt aufrechterhalten. Die Erwerbsbasis ist im allgemeinen so knapp, daß ein Zusatzerwerb auf dem Meer gesucht werden muß. So ergänzt - vor allem im Süden - der Fischfang während der Wintermonate (Hering, Kabeljau) die sommerliche Landwirtschaft.

Für den Nord-Süd-Verkehr sind die Fjorde ein arges Hindernis. Große Autofähren verbinden die fahrbaren Straßenstücke vor den Fjordausgängen und wichtigere Durchgangsrouten. Kleinfähren dienen weiter fjordeinwärts dem Lokalverkehr. Im Landesinnern verlaufen $\mathrm{Paßstraßen} \mathrm{über} \mathrm{die} \mathrm{öden} \mathrm{Fjell-Hochflächen,} \mathrm{oft} \mathrm{in} \mathrm{gewagten} \mathrm{Kehren}$ zu den Fjordenden absteigend. Gerade diese Stellen sind aber heute für den Tourismus bekannte Anziehungspunkte. Besonders geschätzt ist der 1955 fertiggestellte, $26 \mathrm{~km}$ lange Oerne-Vegen (Adlersweg), eine Aussichtsstraße, die vom hintersten Geirangerfjord nach Ytredal am oben erwähnten Nordalsfjord führt. Dank der tief ins Gebirge hineinreichenden Fahrwasser lassen sich weit im Landesinnern begeisternde See-LandReisen durchführen, die sich im Sommer stets wachsender Beliebtheit erfreuen.

\title{
VOM NILDELTA
}

\author{
ERNST LEEMANN
}

Das Wort Herodots, daß Ägypten ein Geschenk des Nils sei, gilt heute wie jemals; denn ohne das Bewässerungswunder wäre das Niltal Wüste wie seine Nachbarschaft in Ost und West.

Der Nil hat sich im Laufe der Zeit, wie jeder andere Fluß, in die östliche Wüstentafel der Sahara eingeschnitten. Fünf Etappen sind durch ebensoviele Erosionsterrassen festgestellt. Auf der zweitobersten, also schon in den Anfängen der Talbildung, ist paläolithische Besiedlung durch Funde von Steinwerkzeugen sichergestellt. Die Besiedlung hat also auch vorhistorisch hier ein hohes Alter. 